Research Article

\title{
Green Economic Efficiency Evaluation Based on the GMM Model
}

\author{
Haohui Wang $(\mathbb{D}$ and Gang Peng \\ School of Statistics, Southwestern University of Finance and Economics, Chengdu 611130, China \\ Correspondence should be addressed to Haohui Wang; wanghh_2020@smail.swufe.edu.cn
}

Received 11 October 2021; Revised 2 November 2021; Accepted 12 November 2021; Published 16 December 2021

Academic Editor: Sang-Bing Tsai

Copyright (c) 2021 Haohui Wang and Gang Peng. This is an open access article distributed under the Creative Commons Attribution License, which permits unrestricted use, distribution, and reproduction in any medium, provided the original work is properly cited.

\begin{abstract}
This paper uses a panel data sample of 30 resource-based cities (hereinafter referred to as R-B cities) in China from 2009 to 2019 , constructs the green economic efficiency level (hereinafter referred to as GEE) using the super-SBM model, incorporates the GEE value into the endogenous economic growth model, combines the difference equation and the level equation, and estimates the relationship between the green efficiency level and economic growth using the systematic GMM method. The study came to the following major conclusions: First, green development in Chinese resource-based cities is moderately high, and green economic efficiency varies by region, with a relatively low level of GEE in the central region and a relatively high level of GEE in the eastern and western regions. Second, on both static and dynamic dimensions, Chinese resource-based cities can be classified into seven types based on their level of green development. Third, the GEE of Chinese resource-based cities has a significant positive relationship with economic growth, with the effect of green economic efficiency on economic growth being stronger in the central and northeastern regions.
\end{abstract}

\section{Introduction}

Green economy is based on the traditional economy, making full use of traditional factors such as social labor, capital, and natural resources, while using clean production technology to reproduce various resources and promote economic growth while avoiding resource waste and environmental pollution [1]. Green economy is one of the important ways for resource-based cities to break the development bottleneck. The green economy development model can be used to alleviate the conflict between urban economic development and the environment when it occurs [2].

Domestic and foreign scholars have carried out very rich research on green economy from the international level. Khan et al. concentrated on the connection between financial development and natural maintainability based on panel data of 43 different countries around the world [3]; Wang et al. studied the relationship between foreign opening and green technological progress based on the comparison of two countries [4]; Huang and Hua studied the bioenergy intensity of European countries [5]; from the study of China, at the macronational level, Yuan and Xiang explored the impact of FDI on carbon emissions in China [6]; at the regional and provincial levels, Sun et al. studied the impact of innovation on ecoefficiency from a provincial perspective [7]; Zhao et al. explored the green transition in China [8]; and Cui et al. studied the utility of carbon emissions on the provincial economy of China [9]. More extensive studies on China's green economy have cut from the perspective of industrial transfer [10-16], proposing to optimize the industrial structure and achieve industrial upgrading; some scholars have analyzed the development of green economy from the policy perspective [17-19], for example, how different environmental regulatory instruments affect energy efficiency. In addition, there is also literature on technological progress and firm productivity from the perspective of microfirms [20]. 
There is also a lot of literature studying green economy from the city level [21, 22], but most of them analyze the overall analysis by province, and there is a lack of studies that construct a comprehensive evaluation system of green economy development levels from the perspective of resource-based cities. This paper focuses on resource-based cities in China and constructs green economic efficiency indicators, taking into account the specific geographical location and resource endowment of each city and the results of the 13th Five-Year Plan and the 14th Five-Year Plan. The study adds a specific and up-to-date urban perspective with Chinese development characteristics.

In addition, the traditional green economy is based on the macroeconomic and industrial perspectives, market orientation, traditional economy, and the harmonious development of economy and environment. This paper breaks this tradition and proposes that the green economy should be based on clean production technology from the perspective of inputs and outputs of production functions, making full use of various inputs, preventing environmental pollution and resource waste, and achieving green and sustainable economic development.

\section{Description of Variables, Model Setting, and Methodological Introduction}

\subsection{Introduction to the Concept of Green Economic Efficiency and Accounting Methods}

2.1.1. Concept Definition. Efficiency was originally a physical concept that reflected the degree of energy loss in the process of mechanical behavior. It can be divided into technical efficiency and configuration efficiency in the economic field. On the premise that production technology and market prices remain unchanged, the British economist Farrell defines the technical efficiency of the input point of view as the ratio of the minimum cost required to produce a certain number of products to the actual cost of consumption. Allocation efficiency refers to the optimal combination of investment production factors of specific technology and limited resources so as to achieve the goal of minimizing costs or maximizing profits. This paper mainly studies technical efficiency to reflect the development level of green economy in resource-based cities. Green economic efficiency is based on resource input and environmental cost considerations and evaluates the economic efficiency indicators of a country or region. Specifically, it includes two aspects: (1) the effectiveness of the input elements in the production process; (2) the "green" economic benefits after the integration of environmental element inputs and environmental pollution factors. The green economic efficiency assessment is shown in Figure 1.

2.1.2. Accounting Methods. In this paper, the super-SBM model is used for accounting for green economic efficiency. The model is shown in the following equation:

$$
\begin{aligned}
& \rho^{*}=\min \frac{(1 / m) \sum_{i=1}^{m}\left(x_{i} / x_{i 0}\right)}{(1 / n+k)\left(\sum_{r=1}^{n}\left(y_{r} / y_{r 0}\right)+\sum_{l=1}^{k}\left(b_{l} / b_{l 0}\right)\right)}, \\
& \text { s.t. }\left\{\begin{array}{l}
\bar{x} \geq \sum_{j=1, \neq 0}^{J} \lambda_{j} x_{j}, \\
\bar{y} \leq \sum_{j=1, \neq 0}^{J} \lambda_{j} y_{j}, \\
\bar{b} \leq \sum_{j=1, \neq 0}^{J} \lambda_{j} b_{j}, \\
\bar{x} \geq x_{0}, \bar{y} \leq y_{0}, \bar{b} \geq b_{0}, \bar{y} \geq 0, \overline{\lambda_{j}} \geq 0,
\end{array}\right.
\end{aligned}
$$

where $\bar{x}, \bar{y}, \bar{b}$ slack variables denote inputs, desired outputs, and undesired outputs, respectively. $\lambda_{j}$ denotes the weight vector of inputs and outputs, i.e., the envelope multiplier. $\rho^{*}$ is the efficiency value of the decision unit, indicating the green economic efficiency value to be measured. The larger the $\rho^{*}$, the more efficient the green economy.

In this paper, the input factors include physical capital, human capital, energy capital, and labor; the desired output is the GDP of each resource-based city; the nondesired output includes industrial wastewater emissions, industrial $\mathrm{SO}_{2}$ emissions, and industrial smoke emissions of each city.

2.2. Econometric Model Determined Based on the Extended Solow Model. In the study of economic growth, Mankiw-Romo-Will (MRW) and Barro and Sala-Martin first developed growth regression equations on growth models. In this paper, we build the extended Solow growth model based on the MRW study.

The extended Solow growth model treats human capital as a factor input of the same nature as physical capital and labor and is a variation of the Lucasian human capital externality model with the equation as follows:

$$
\begin{aligned}
& Y_{i, t}=A F\left(K_{i, t}, L_{i, t}, H_{i, t}\right), \\
& Y_{i, t}=A K_{i, t}^{\alpha}, L_{i, t}^{\beta}, H_{i, t}^{\gamma} e^{\mu_{t}},
\end{aligned}
$$

where $Y_{i, t}, K_{i, t}, L_{i, t}, H_{i, t}$ represent the GDP, capital, labor, and human capital, respectively, $A$ represents the technological progress, $\alpha, \beta$, and $\gamma$ represent the capital output elasticity, labor output elasticity, and human capital output elasticity, and $\mu_{t}$ is a random interference term.

Drawing on previous references, assuming that $A$ is a one-dimensional function $A(\cdot)$, GEE is considered as the "enabler" of the society-wide production efficiency $A$, which is included in the function of the efficiency multiplier $A$. Then, we have

$$
A(G E E)=A_{i, 0} \times G E E_{i, t}^{\delta}
$$

where $A_{i, 0}$ denotes the initial society-wide production efficiency level and $\delta$ denotes the impact parameter of green economic efficiency. 


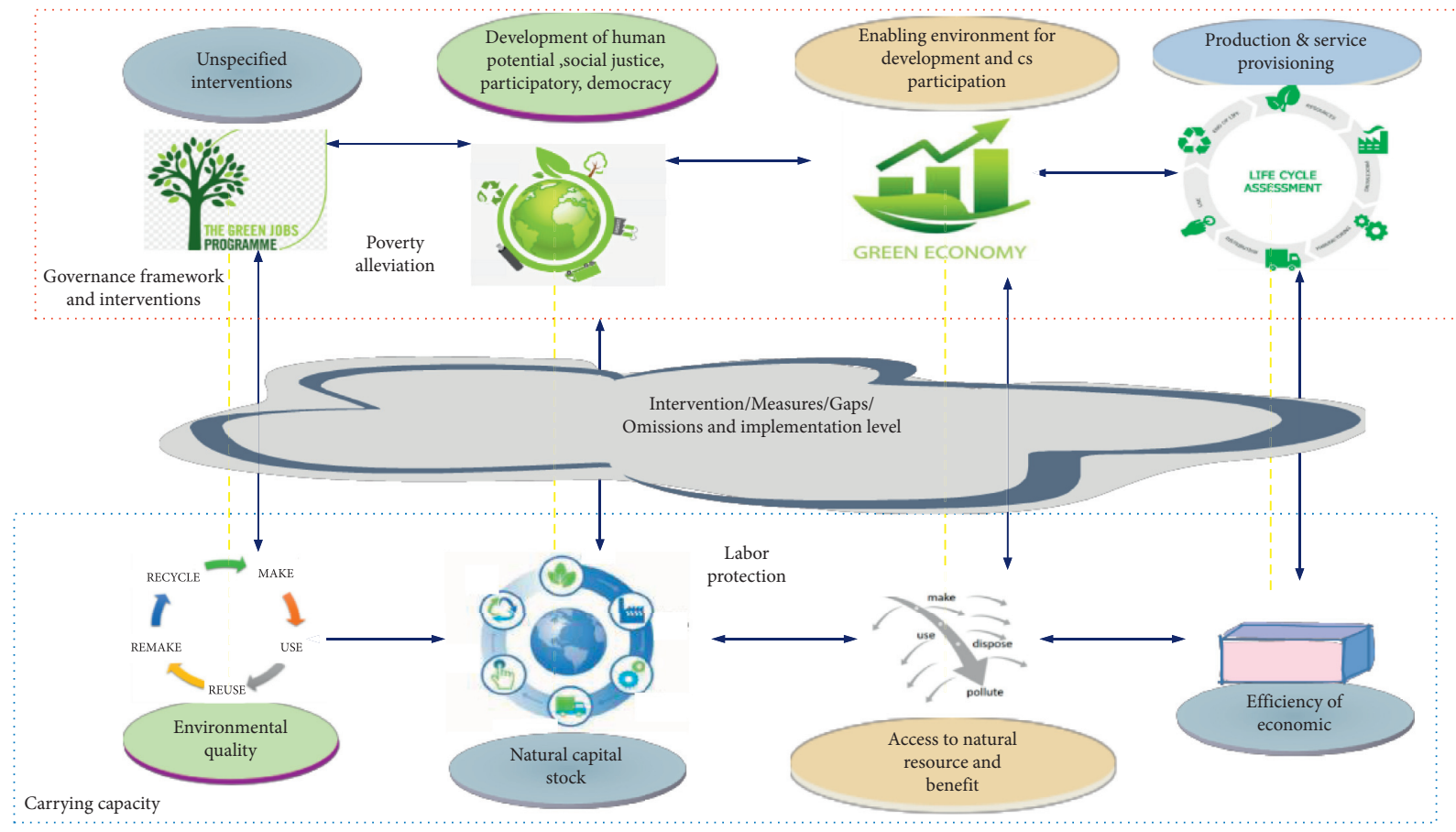

Figure 1: Green economic efficiency assessment.

Bringing the abovementioned equation into the extended Solow growth model and logarithmically processing the model yields the following transformation model:

$$
\begin{aligned}
\ln Y_{i, t}= & \ln A_{i, 0}+\delta \ln G E E_{i, t}+\alpha \ln K_{i, t}+\beta \ln L_{i, t} \\
& +\gamma \ln H_{i, t}+\varepsilon_{i, t} .
\end{aligned}
$$

To avoid biased estimates due to the omission of other important explanatory variables, this paper extends the abovementioned equation into a dynamic model by introducing a lagged term for the dependent variable. The dynamic model also has the advantage that when some of the explanatory variables in the model are endogenous, the endogeneity bias of the model can be eliminated through the dynamic panel data measures, thus obtaining consistent estimates of the coefficients of these explanatory variables. Finally, the paper also considers a set of control variables, including R\&D investment (RD) and industry structure (IS). The final model is obtained as follows:

$$
\begin{aligned}
\ln Y_{i, t}= & \ln A_{i, 0}+\phi \ln Y_{i, t-1}+\delta \ln G E E_{i, t}+\alpha \ln K_{i, t} \\
& +\beta \ln L_{i, t}+\gamma \ln H_{i, t}+\varphi_{1} \ln R D_{i, t} \\
& +\varphi_{2} \ln I S_{i, t}+\varepsilon_{i, t} .
\end{aligned}
$$

\subsection{Measurement Methods and Stability Tests}

2.3.1. GMM Estimation. Generalized moment estimation is currently one of the most effective methods to solve the endogeneity problem of dynamic panel models. Anderson and Hsia used the first-order difference and selected the second-order lagged term of the dependent variable and the second-order difference lagged term as the instrumental variables $\mathrm{AH}$. This method gives theoretically consistent coefficient estimates, but it is invalid. Arellano and Bond (1991) gave a differential generalized moment estimation method based on the $\mathrm{AH}$ instrumental variable method, which uses the lagged term of the dependent variable up to period $t-2$ as the first-order differential lagged term of the dependent variable. Consistent and more efficient estimation results were obtained. However, further studies have shown that differential GMM estimators have poor finite sample properties and are more susceptible to weak instrumental variables, making the estimates biased. Combined with more information in the level equation, SYSGMM proved to be a more effective estimation method. In this paper, the SYS-GMM is used for estimation tests. The schematic diagram of the GMM model is shown in Figure 2.

2.3.2. Stability Tests. Further study shows that the presence of unobserved individual fixed effects will lead to upward biased estimates of the mixed OLS estimates of the lagged coefficients of the dependent variable, while the fixed-effects estimates in the "small time dimension and large crosssectional dimension" panels will produce downward biased estimates. Therefore, the consistent estimates of the coefficients of the lagged terms of the dependent variable will be in between the POOLED estimates and the FE estimates. This paper performs mixed OLS and fixed-effects estimation on the dynamic panel model to test the stability of the systematic GMM estimates.

\section{Experimental Overview}

In this paper, Chinese resource-based cities from 2009-2019 are selected as research objects, and the super-SBM model is 


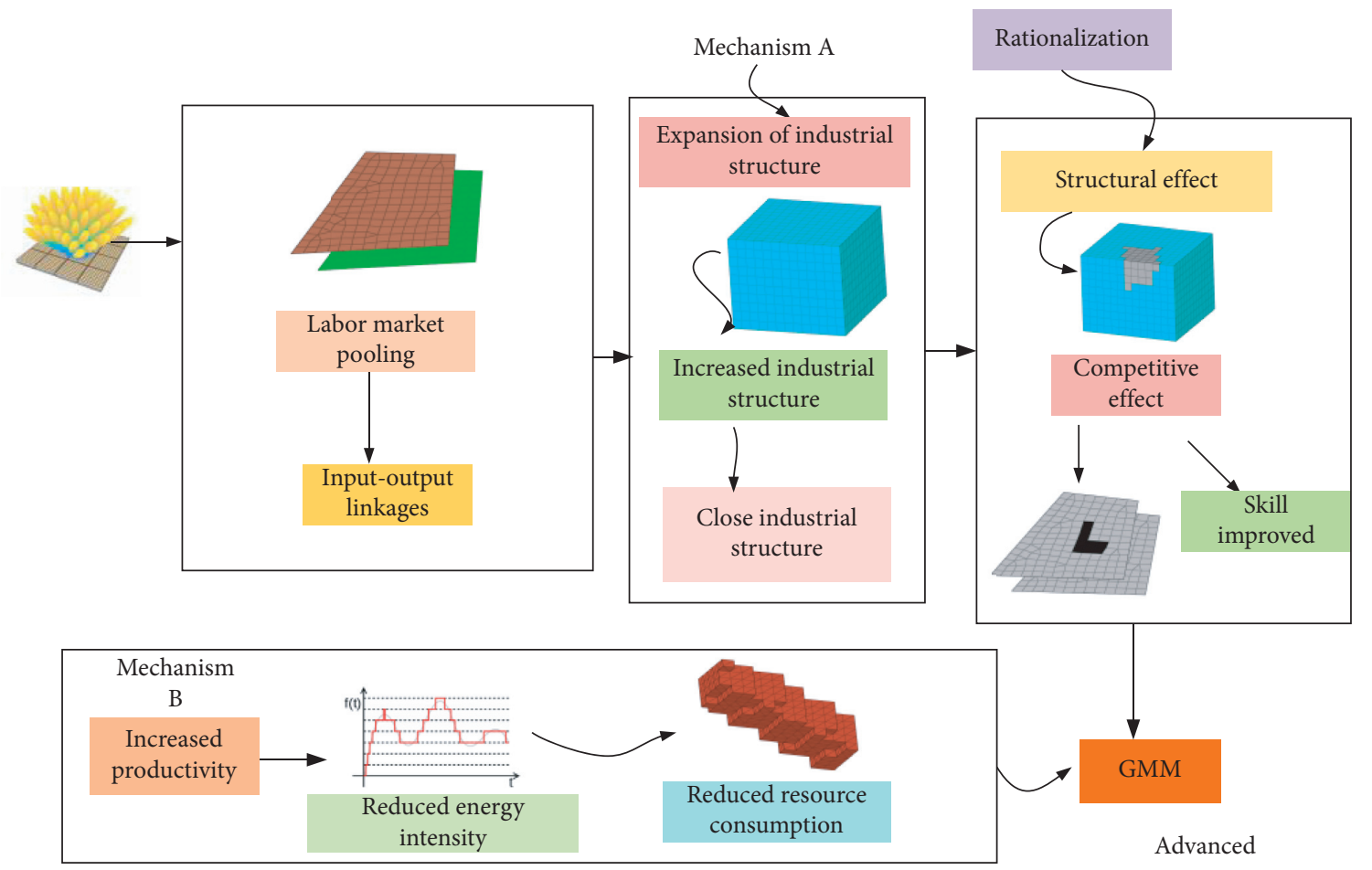

FIgURE 2: Schematic diagram of the GMM model.

used to measure and obtain the green economic efficiency (GEE) values and conduct empirical analysis on the impact of GEE on the local economy.

\subsection{Analysis on GEE}

3.1.1. Evolutionary Characteristics of GEE. The evolution of green economic efficiency is shown in Figure 3.

First, at the national level, the average GEE value of R-B cities in China is 0.55 , which generally indicates that the economic development and green development of R-B cities in China are at a medium-to-high level. Since the 1980s, the Chinese government has attached great importance to the transformation and upgrading of R-B cities and issued the opinions on promoting the sustainable development of resource-based cities in 2007, which experienced short-term policy effect delay (the GEE value in 2009 was only 0.38 ). The level of green development in Chinese R-B cities has improved year by year and reached a higher level of green development with an efficiency value of 0.78 in 2019 .

Second, at the regional level, the western region has the highest level of green development (with an average efficiency value of 0.61) and opened a significant gap with other regions in 2019 (with an efficiency value of 0.87); the eastern region follows closely (with an average efficiency value of 0.56 ), and the level of green development has increased year by year; the northeast region ranks third, but the efficiency level shows an inverted U-shaped development, reaching a peak of 0.68 in 2013, and from 2015, its efficiency value has not exceeded 0.5; the central region has the lowest green development level among the four regions (average efficiency value of 0.46 ), but the development momentum is strong, with an efficiency value of only 0.29 in 2009, and after 11 years of development, the efficiency value of the region has increased to 0.78 in 2019, and the green development level has surpassed that of the eastern region.

3.1.2. GEE Dimensional City Classification. The Chinese government classifies R-B cities into four major categories according to the degree of resource exploitation. Based on the level of GEE, this paper classifies Chinese R-B cities into seven categories from both static and dynamic dimensions. The classification summary is shown in Table 1 .

From a static perspective, Chinese R-B cities are divided into three categories according to the absolute amount of GEE. The first category is "high-quality" cities, which are at the head of R-B cities in terms of GEE and are green economic benchmark cities responding to China's "high-quality" development strategy. The second category is "green potential" cities, which have average green development level and have more room for efficiency improvement. The third category is "green warning" cities. The green efficiency of these cities is always at the bottom, and the health of economic development needs to be improved.

Typical cities of "high quality" include Ezhou, Xuzhou, Zigong, and Baoji. Taking Xuzhou as an example, during the 13th Five-Year Plan, Xuzhou implemented the management of coal mining sinkhole and improved the benefits of the sinkhole so as to eventually change from "a city of coal ash and half a city of soil" to "a city of green mountains and half a city of lake"; from the 14th Five-Year Plan, Xuzhou will implement the map, systematically build " 876 " support 


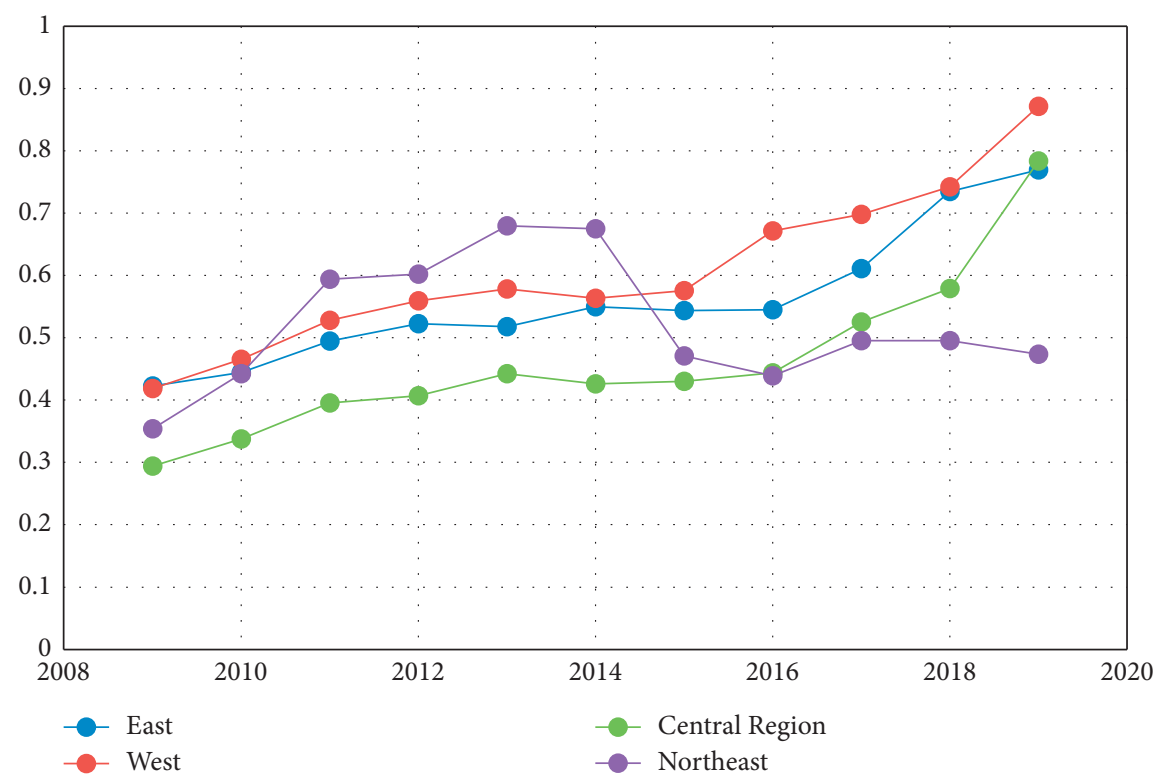

FigURE 3: Evolution of green economy efficiency by region.

TABle 1: Classification of resource-based cities in China based on green economic efficiency values.

\begin{tabular}{lccc}
\hline City classification & & Measurement indicators & Typical city \\
\hline \multirow{4}{*}{ Static dimension } & High-quality type & GEE value above 0.8 & Ezhou, Xuzhou, Zigong, and Baoji \\
& Potential type & GEE values between 0.5 and 0.8 & Zhuzhou, Luzhou, Luoyang, and Suqian \\
& Early warning type & GEE value below 0.5 & Jilin, Shaoguan, Handan, and Shizuishan \\
\hline & Reform breakthrough type & GEE growth rate at $100 \%$ or more & Karamay, Wuwei, Anshun, and Luoyang \\
Stable growth type & GEE growth rate between $50 \%$ and $100 \%$ & Maanshan, Nanyang, Hezhou, and Panjin \\
& Stable development type & GEE growth rate below 50\% & Qujing, Huzhou, Tangshan, and Erdos \\
& Decline and fall type & GEE reverse growth & Baotou \\
\hline
\end{tabular}

systems, and scientifically determine more than 70 key projects of green circular economy, and the total investment will be close to 40 billion.

"Potential" cities include Zhuzhou, Luzhou, Luoyang, and Suqian. Zhuzhou, for example, was once listed among the top ten polluted cities in China in the early years but has become a typical sample city of green development in Hunan Province in recent years. Since 2013, Zhuzhou has shut down more than 1,300 polluting and backward enterprises and vigorously developed three major power industries: rail transportation, general aviation, and new energy vehicles, and now, Zhuzhou's rail transportation output value has exceeded 100 billion, and electric locomotives, rolling stock, and urban railways have been exported to more than 70 countries, making it a mobile "Chinese business card."

"Early warning" cities include Jilin, Shaoguan, Handan, and Shizuishan. Jilin city, for example, is located in the old industrial zone in the northeast, with a single industrial structure, and its economic development mainly depends on resource extraction, and the total amount of "three wastes" is large, so it is urgent to strengthen the upgrading of industrial structure and find sustainable industries for the city.

From a dynamic perspective, China's R-B cities are divided into four categories according to their GEE growth rate. The first category is "reform breakthrough" cities, which have achieved a surge in green economic efficiency after 11 years of development, which shows that these cities have achieved significant reform breakthroughs in industrial transformation and technological innovation and are worth studying. The second category is "stable growth." The green efficiency of these cities has been increasing year by year, and they are the benchmark cities of green economic development. The third category is "stable development." The green efficiency of these cities has not increased much, and they maintain stable development all year round. The fourth category is "declining," in which the green development level of these cities achieves negative growth, and the efficiency of input and output decreases.

The typical cities of "reform breakthrough type" are Karamay, Wuwei, Anshun, and Luoyang. As a typical city that relies on resources, Karamay realized the importance of green development and industrial transfer early on, relied on its own advantages in location, made efforts in tourism and trade, and came out with a special development path that coordinated economic construction with ecological and environmental protection. From the data, it can be seen that its green economic efficiency value in 2019 has increased 2.35 times compared with 2009 .

Most of the remaining cities are of the "stable growth" and "stable development" types. Baotou belongs to the 
TABLe 2: Full sample estimation.

\begin{tabular}{|c|c|c|c|c|}
\hline & POOLED & FE & SYS-GMM (one step) & SYS-GMM (two steps) \\
\hline $\operatorname{lngdp}_{\mathrm{i}, t-1}$ & $0,57539^{* * *}(0.0596)$ & $0.2860^{* * *}(0.0332)$ & $0.5750^{* * *}(0.0736)$ & $0.4224^{* * *}(0.1085)$ \\
\hline $\operatorname{lngee}_{i, t}$ & $0.2681^{* * *}(0.0443)$ & $0.4903^{* * *}(0.0292)$ & $0.2682^{* * *}(0.0608)$ & $0.3527^{* * *}(0.0691)$ \\
\hline $\operatorname{lnk}_{\mathrm{i}, \mathrm{t}}$ & $0.1246^{* * *}(0.0256)$ & $0.0246^{* * *}(0.0213)$ & $0.1247^{* * *}(0.0312)$ & $0.1563^{* * *}(0.0040)$ \\
\hline $\operatorname{lnl}_{\mathrm{i}, \mathrm{t}}$ & $0.2190^{* * *}(0.0322)$ & $0.2716^{* * *}(0.0224)$ & $0.2189^{* * *}(0.0403)$ & $0.2765^{* * *}(0.0595)$ \\
\hline $\operatorname{lnh}_{\mathrm{i}, \mathrm{t}}$ & $0.0104(0.0071)$ & $-0.0066(0.0169)$ & $0.0105(0.0095)$ & $0.0441(0.0327)$ \\
\hline $\operatorname{lnrd}_{i, t}$ & $0.0259^{* * *}(0.0074)$ & $0.0323^{* * *}(0.0082)$ & $0.0260^{* *}(0.0107)$ & $0.0442^{* *}(0.0221)$ \\
\hline $\operatorname{lnis}_{i, t}$ & $0.1351^{* * *}(0.0283)$ & $0.0902^{* *}(0.2828)$ & $0.1347^{* * *}(0.0390)$ & $0.1538^{* *}(0.0709)$ \\
\hline $\operatorname{AR}(1)$ & & & {$[0.0020]$} & {$[0.0120]$} \\
\hline $\operatorname{AR}(2)$ & & & {$[0.5430]$} & {$[0.7610]$} \\
\hline Hansen test & & & {$[1.0000]$} & {$[1.0000]$} \\
\hline
\end{tabular}

$(1)^{* * *},{ }^{* *}$, and ${ }^{*}$ represent the statistical tests that can pass the significance level of $1 \%, 5 \%$, and $10 \%$, respectively; (2) data in () are standard deviations, and data in [ ] are $p$ values; (3) $\mathrm{AR}(1)$ and $\mathrm{AR}(2)$ represent Arellano-Bond's test statistics, which are used to examine whether there are first-order and secondorder autocorrelation in the primary difference residual series, with the original hypothesis that there is no existence of autocorrelation; (4) the Hansen test is used to examine whether there is overidentification of moment conditions, and its original hypothesis is that the selection of instrumental variables is valid. The following table is the same.

TABLE 3: Subregional one-step system GMM estimation.

\begin{tabular}{lcccc}
\hline & East & West & Central region & Northeast \\
\hline $\operatorname{lngdp}{ }_{\mathrm{i}, t-1}$ & $0.5533^{* * *}(0.0623)$ & $0.7290^{* * *}(0.0886)$ & $0.2209^{*}(0.1161)$ & $0.3513^{* * *}(0.1146)$ \\
$\operatorname{lngee}_{\mathrm{i}, \mathrm{t}}$ & $0.3146^{* * *}(0.0770)$ & $0.1921^{* * *}(0.0638)$ & $0.5228^{* * *}(0.1128)$ & $0.4577^{* * *}(0.0323)$ \\
$\operatorname{lnk}_{\mathrm{i}, \mathrm{t}}$ & $0.1367^{* * *}(0.0377)$ & $0.0765^{*}(0.0401)$ & $0.2145^{* * *}(0.0399)$ & $-0.0689(0.1215)$ \\
$\ln _{\mathrm{i}, \mathrm{t}}$ & $0.3134^{* * *}(0.0578)$ & $0.1209^{* *}(0.0554)$ & $0.2663^{* * *}(0.0267)$ & $0.3183(0.2888)$ \\
$\operatorname{lnh}_{\mathrm{i}, \mathrm{t}}$ & $-0.0107(0.0212)$ & $0.0149(0.0110)$ & $0.0631^{* * *}(0.0153)$ & $0.1618^{* * *}(0.0373)$ \\
$\operatorname{lnd}_{\mathrm{i}, \mathrm{t}}$ & $0.0111(0.0164)$ & $-0.0006(0.0135)$ & $0.0809^{* * *}(0.0156)$ & $0.0943^{* * *}(0.0150)$ \\
$\ln \mathrm{s}_{\mathrm{i}, \mathrm{t}}$ & $0.1262^{* *}(0.0586)$ & $0.1487^{* * *}(0.0283)$ & $0.0969^{*}(0.0583)$ & $-0.0351(0.1158)$ \\
$\mathrm{AR}(1)$ & {$[0.0290]$} & {$[0.0260]$} & {$[0.0840]$} & {$[0.0920]$} \\
$\mathrm{AR}(2)$ & {$[0.5520]$} & {$[0.8720]$} & {$[0.2220]$} & {$[0.1870]$} \\
Hansen test & {$[1.0000]$} & {$[1.0000]$} & {$[1.0000]$} & {$[1.0000]$} \\
\hline
\end{tabular}

"declining" type of cities, and its 2019 data had achieved a reverse growth in efficiency compared to 2009. Baotou has three main problems: first, the shortage of resources, second, the failure to find comparative advantages based on its own characteristics, and third, the industrial structure and technological innovation are still lagging behind.

3.2. GMM Analysis of the Endogenous Economic Growth Model Incorporating GEE Elements. The GEE values constructed through the super-SBM model are incorporated into the endogenous economic growth model, and the impact of GEE on economic growth is explored based on equation (5). The results of the full sample estimation are shown in Table 2.

3.2.1. Full Sample Analysis. One-step systematic GMM and two-step systematic GMM estimations were performed for the full sample, and robustness tests were conducted using mixed- and fixed-effects models. The results show that the systematic GMM estimates of the coefficients of the lagged terms of the dependent variable will be between the mixed estimates and the fixed-effects estimates, so the systematic GMM estimates are judged to be robust, and the regression results are analyzed below.

Due to the downward bias in the standard deviation of the two-step GMM estimates and the unreliability of the approximate asymptotic distribution of the estimators, the one-step method systematic GMM, which has more reliable estimators, prevails in the analysis.

The estimation results show that there is a significant positive relationship between green economic efficiency (lngee) and economic growth (lngdp), indicating that increasing green economic efficiency has a significant contribution to economic growth. Specifically, for every $1 \%$ increase in original GEE, on average, the GDP of Chinese $\mathrm{R}-\mathrm{B}$ cities increases by $0.2682 \%$ of the original.

In terms of other explanatory variables, physical capital factor (lnk), labor force (lnl), and economic growth (lngdp) are significantly positively correlated, indicating that twofactor inputs make significant contributions to China's economic growth.

In terms of control variables, input research and development (lnrd) and industrial structure (lnis) also have a significant positive effect on economic growth (lngdp), which also agrees with expectations.

3.2.2. Comparison of Regional Differences. Systematic GMM estimation was performed on the data from eastern, western, central, and northeastern China by administrative regions of China, and the estimated results are shown in Table 3. From the statistical test results, the $p$ value of the Hansen test is 1 , so the original hypothesis is accepted; that is, the instrumental variables are selected validly; the Arellano-Bond AR (2) test also shows that there is no second-order 
autocorrelation in the model error term. Therefore, the results of the subregional estimation can be considered to be confident.

From the regression results, it is clear that the impact of GEE on economic growth is significantly positive in all regions, with the highest impact coefficient (0.5228) in the central region, followed by the northeastern region and the smaller impact coefficient of green economic efficiency on economic growth in the eastern and western regions. Combined with the analysis of the efficiency values of each region, the GEE values of the east and west regions are already at a higher level, and their marginal effects on economic growth are weakened; on the contrary, the central and northeastern regions have a lower level of green development, and they show a greater marginal effect on economic growth.

\section{Conclusions}

This paper has studied the GEE of R-B cities in China and explored the impact of GEE on economic growth. The main findings are summarized as follows.

First of all, the analysis of the evolution of GEE of Chinese R-B cities shows that, at the national level, the health of economic development and green development of Chinese R-B cities are at the middle to upper level; by region, the western region has the highest level of green development and has the tendency to widen the gap with other regions, the eastern region ranks second, and the central region ranks at the bottom, but the level of efficiency is improving rapidly, and its economic efficiency value had surpassed that of the eastern region in 2019.

Furthermore, based on the level of GEE, China's R-B cities can be divided into seven categories. At the static level, there are three categories, namely, "high quality," "potential," and "early warning;" at the dynamic level, and there are four categories, namely, "reform breakthrough," "stable growth," "stable development," and "decline and fall."

At last, the GMM analysis of GEE into the endogenous economic growth model yields confident and robust estimation results, which show that there is a significant positive correlation between GEE and economic growth; the effect of green economic efficiency on economic growth is different in different regions, with the largest effect being in the central region and the smallest effect on economic growth being in the western region, and the size of the effect is related to each region's current existing one. The size of the impact is related to the current efficiency level of each region.

The possible contributions and innovations of this paper are in the following aspects.

The first is the complement of perspectives. Most of the current studies on green economic efficiency are based on provincial-level panel data, and there is a lack of research on cities, especially on resource-based cities in China. This paper focuses on Chinese resource-based cities, takes into account the specific geographical location and resource endowment of each resource-based city, and combines the results of the 13th Five-Year Plan and the 14th Five-Year Plan to provide a specific and updated perspective on resource-based cities with Chinese development characteristics for the study of green economic efficiency.

The next is innovation in thinking. The Chinese government classifies R-B cities into four categories according to the degree of resource exploitation. Based on the level of GEE, this paper creatively divides resource-based cities into seven categories from both static and dynamic dimensions, providing new ideas for planning and governing R-B cities in China and around the world.

The final one is the extension of the method. The green economic efficiency values constructed through the superSBM model are incorporated into the endogenous economic growth model, and the relationship between the green efficiency level and economic growth is estimated through the systematic GMM method by combining the difference equation and the level equation.

\section{Data Availability}

The data used to support the findings of this study are included within the article.

\section{Conflicts of Interest}

The authors declare no conflicts of interest in this article.

\section{Acknowledgments}

This work was supported by the Youth Project of National Social Science Fund, Theory, Method, and Application of Green Finance Statistics in China (18CTJ005).

\section{References}

[1] Y. Cao, J. Liu, Y. Yu, and G. Wei, "Impact of environmental regulation on green growth in China's manufacturing industry-based on the malmquist-luenberger index and the system GMM model," Environmental Science and Pollution Research, vol. 2, no. 3, pp. 1-8, 2020.

[2] W. Jin, H. Q. Zhang, S. S. Liu, and H. B. Zhang, "Technological innovation, environmental regulation, and green total factor efficiency of industrial water resources," Journal of Cleaner Production, vol. 211, no. 1, pp. 61-69, 2019.

[3] S. A. Rehman Khan, Y. Zhang, M. Anees, H. Golpîra, A. Lahmar, and D. Qianli, "Green supply chain management, economic growth and environment: a GMM based evidence," Journal of Cleaner Production, vol. 185, no. 5, pp. 588-599, 2018.

[4] S. Wang, X. Wang, F. Lu, and F. Fan, "The impact of collaborative innovation on ecological efficiency-empirical research based on China's regions," Technology Analysis \& Strategic Management, vol. 2, no. 8, pp. 1-5, 2020.

[5] J. Huang and Y. Hua, "Eco-efficiency convergence and green urban growth in China," International Regional Science Review, vol. 42, no. 3, pp. 307-334, 2019.

[6] B. Yuan and Q. Xiang, "Environmental regulation, industrial innovation and green development of Chinese manufacturing: based on an extended CDM model," Journal of Cleaner Production, vol. 176, no. 6, pp. 895-908, 2018.

[7] Y. Sun, J. Du, and S. Wang, "Environmental regulations, enterprise productivity, and green technological progress: 
large-scale data analysis in China," Annals of Operations Research, vol. 5, no. 6, pp. 1-6, 2019.

[8] M. Zhao, F. Liu, W. Sun, and X. Tao, "The relationship between environmental regulation and green total factor productivity in China: an empirical study based on the panel data of 177 cities," International Journal of Environmental Research and Public Health, vol. 17, no. 15, pp. 52-87, 2020.

[9] H. Cui, X. Liu, and Q. Zhao, "Which factors can stimulate China's green transformation process? from provincial aspect," Polish Journal of Environmental Studies, vol. 30, no. 1, pp. 1-14, 2020.

[10] B. Cao and S. Wang, "Opening up, international trade, and green technology progress," Journal of Cleaner Production, vol. 142, no. 2, pp. 1002-1012, 2017.

[11] C. Wang and Y. J. Zhang, "Does environmental regulation policy help improve green production performance? evidence from China's industry," Corporate Social Responsibility and Environmental Management, vol. 27, no. 2, pp. 937-951, 2020.

[12] M. Alsaleh and A. Abdul-Rahim, "Bioenergy intensity and its determinants in european continental countries: evidence using GMM estimation,” Resources, vol. 8, no. 1, pp. 43-45, 2019.

[13] Y. Zhou, J. Fu, Y. Kong, and R. Wu, "How foreign direct investment influences carbon emissions, based on the empirical analysis of Chinese urban data," Sustainability, vol. 10, no. 7, pp. 2163-2167, 2018.

[14] W. Gao, J. Cheng, and J. Zhang, "The influence of heterogeneous environmental regulation on the green development of the mining industry: empirical analysis based on the system GMM and dynamic panel data model," Chinese Journal of Population Resources and Environment, vol. 17, no. 2, pp. 154-175, 2019.

[15] Y. Hu, H. Jiang, and Z. Zhong, "Impact of green credit on industrial structure in China: theoretical mechanism and empirical analysis," Environmental Science and Pollution Research, vol. 1, no. 5, pp. 1-4, 2020.

[16] F. Yang, Y. Cheng, and X. Yao, "Influencing factors of energy technical innovation in China: evidence from fossil energy and renewable energy," Journal of Cleaner Production, vol. 232, no. 2, pp. 57-66, 2019.

[17] W. Li, J. Wang, R. Chen et al., "Innovation-driven industrial green development: the moderating role of regional factors," Journal of Cleaner Production, vol. 222, no. 2, pp. 344-354, 2019.

[18] R. Hashmi and K. Alam, "Dynamic relationship among environmental regulation, innovation, $\mathrm{CO}_{2}$ emissions, population, and economic growth in OECD countries: a panel investigation," Journal of Cleaner Production, vol. 231, no. 1, pp. 1100-1109, 2019.

[19] F. Ganda, "The impact of innovation and technology investments on carbon emissions in selected organisation for economic Co-operation and development countries," Journal of Cleaner Production, vol. 217, no. 7, pp. 469-483, 2019.

[20] R. Li and T. Sun, "Research on impact of different environmental regulation tools on energy efficiency in China," Polish Journal of Environmental Studies, vol. 29, no. 6, pp. 1-5, 2020.

[21] J. Hou, T. S. H. Teo, F. Zhou, M. K. Lim, and H. Chen, "Does industrial green transformation successfully facilitate a decrease in carbon intensity in China? an environmental regulation perspective," Journal of Cleaner Production, vol. 184, no. 4, pp. 1060-1071, 2018.

[22] K. Zhang, Z. Y. Zhang, and Q.-M. Liang, "An empirical analysis of the green paradox in China: from the perspective of fiscal decentralization," Energy Policy, vol. 103, no. 3, pp. 203-211, 2017. 